\title{
Erratum to: Characterization of graphomotor functions in individuals with Parkinson's disease and essential tremor
}

\author{
Nan-Ying $\mathrm{Yu}^{1}$ • Arend W. A. Van Gemmert ${ }^{2}$ - Shao-Hsia Chang ${ }^{3}$
}

Published online: 3 October 2016

(C) Psychonomic Society, Inc. 2016

Erratum to: Behav Res

10.3758/s13428-016-0752-y

The correct corresponding author is Shao-Hsia Chang. The correct affiliation of Nan-Ying Yu is Department of Physical Therapy, I-Shou University.

The online version of the original article can be found at http://dx.doi. org/10.3758/s13428-016-0752-y.

Shao-Hsia Chang

stacey12@mail.isu.edu.tw

Nan-Ying Yu

ying@mail.isu.edu.tw

Arend W. A. Van Gemmert gemmert@1su.edu

1 Department of Physical Therapy, I-Shou University, Kaohsiung City, Taiwan

2 School of Kinesiology, Louisiana State University, Baton Rouge, LA 70803, USA

3 Department of Occupational Therapy, I-Shou University, No. 8, Yida Road, Yanchao District Kaohsiung City 82445, Taiwan 